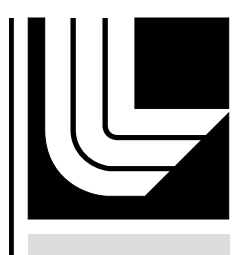

LAW RENCE LIVERMORE N A TIO N A L LABORATORY

\title{
UCRL-TR-217909
}

\section{Chemical Analysis Of Beryllium Shells}

J. Gunther, R. Cook

December 29, 2005 
This document was prepared as an account of work sponsored by an agency of the United States Government. Neither the United States Government nor the University of California nor any of their employees, makes any warranty, express or implied, or assumes any legal liability or responsibility for the accuracy, completeness, or usefulness of any information, apparatus, product, or process disclosed, or represents that its use would not infringe privately owned rights. Reference herein to any specific commercial product, process, or service by trade name, trademark, manufacturer, or otherwise, does not necessarily constitute or imply its endorsement, recommendation, or favoring by the United States Government or the University of California. The views and opinions of authors expressed herein do not necessarily state or reflect those of the United States Government or the University of California, and shall not be used for advertising or product endorsement purposes.

This work was performed under the auspices of the U.S. Department of Energy by University of California, Lawrence Livermore National Laboratory under Contract W-7405-Eng-48. 


\section{Target Area Technologies Program}

Mail Station L-399

Ext: $3-3941$

Date: $\quad$ November 16, 2005

To: Distribution

From: Janelle Gunther, Bob Cook

Subject: Chemical Analysis of Beryllium shells

\section{Summary:}

There is a need to understand the level of high-Z impurities in Beryllium shells prepared by sputter coating. The Ignition Point Design Requirements ${ }^{1}$ state the following: "Except for allowed ingredients, as listed in the ablator composition entries, the ablator material in all layers shall contain sufficiently low impurity levels that the sum over all impurities of atom fraction $* \mathrm{Z}^{2}$ shall be less than or equal to 0.2." This is a tight specification that requires careful materials analysis. Early in the first quarter of FY06, we undertook a study of Be shell impurities via ICP$\mathrm{MS}^{2}$ and determined that the impurity levels in the sputtered shells are very close to the specification.

\section{Experimental:}

To measure trace impurities in Be shells, we followed the standard protocol for ICP-MS. First the Be shells were pyrolized to remove the mandrel and the remaining pieces $(7 \mathrm{mg}$ total amount) were dissolved in high purity nitric acid. This solution was then exposed to an $\mathrm{Ar}$ plasma to atomize and ionize the elements in the sample. The ions were then passed through a series of apertures (cones) and into a high vacuum mass analyzer. The isotopes are identified by their mass-to-charge ratio $(\mathrm{m} / \mathrm{e})$. The results are tabulated on a graph of counts as a function of mass number. The intensity of a specific peak is proportional to the amount of that element in the original sample. The instrument is calibrated for mass dependent sensitivity using concentration standards. A calibration curve is created using the data from these standards. The slope of the linear curve has units of counts per second (CPS)/concentration unit (usually ng/g or ppb). The samples are then run and a signal intensity (CPS) is obtained for one or more isotopes of the element of interest. This CPS is then converted into $\mathrm{ng} / \mathrm{g}$ using the slope determined for the standards. Typical accuracies for this technique are in the several \% range.

The Be sputter targets themselves, S-65 Structural Grade Be Block from Brush-Wellman, have impurity content that is close to the specification. The levels of impurities in Be coupons (Brush Wellman PF-60) are shown in Table 1, accompanied by the calculations for the $\mathrm{Z}^{2}$ weighted sum of atom fraction. Note that the analyses values are only 1 significant figure, the

\footnotetext{
${ }^{1}$ Steve Haan, Ignition Point Design Requirements, Number 1, Rev 0, WBS I.4.1.1

${ }^{2}$ ICP-MS: Inductively-Coupled Plasma Mass Spectrometry. Analysis done in the C\&MS Department.
} 
calculations based on these include more for clarity, but the final sum is only good to about 1 significant figure. The Brush Wellman analysis for the S-65 sputter targets is more limited, but the levels listed in Table 1 are about the same ( 0.08 instead of $0.06 \mathrm{wt} \%$ for Fe the most important variant). The sum of 0.160 is dominated by individual measurements for $\mathrm{Fe}$ and $\mathrm{Ni}$, at 0.066 and 0.024 respectively. The results of the ICP-MS analysis for the Be shells themselves are shown in Table 2. The weighted sum was much higher, 0.554 in this case due to an unexpected amount of $\mathrm{Cu}$ in the sputtered samples. The weighted sum drops to 0.117 when the $\mathrm{Cu}$ is removed. This value does not change appreciable (only to about 0.12) if a small amount of $\mathrm{Cu}$ is taken into account assuming that the level of $\mathrm{Cu}$ should only be what it was in the analyzed coupon (Table 1).

Table 1. Impurities in a Brush Wellman Be coupon (PF-60) based on the Brush Wellman analysis that accompanied the samples. Also shown is the roll-up of these impurities as required to evaluate their level relative to the impurity specification. Conversion from the reported wt $\%$ to atom\% is accomplished by multiplication by (At. W. Be)/(At. W. element).

$\begin{array}{crrlcc}\text { Element } & \mathrm{Z} & \text { At. W. } & \text { wt\% } & \text { atom\% } & \mathrm{Z}^{2 * a t \% / 100} \\ \mathrm{Fe} & 26 & 55.85 & 0.06 & 0.0097 & 0.066 \\ \mathrm{Ni} & 28 & 58.71 & 0.02 & 0.0031 & 0.024 \\ \mathrm{Si} & 14 & 28.09 & 0.02 & 0.0064 & 0.013 \\ \mathrm{Al} & 13 & 26.98 & 0.02 & 0.0067 & 0.011 \\ \mathrm{Cr} & 24 & 52.00 & 0.01 & 0.0017 & 0.010 \\ \mathrm{Ca} & 20 & 40.08 & 0.01 & 0.0022 & 0.009 \\ \mathrm{~Pb} & 82 & 207.19 & 0.002 & 0.0001 & 0.006 \\ \mathrm{C} & 6 & 12.01 & 0.02 & 0.015 & 0.005 \\ \mathrm{Cu} & 29 & 63.54 & 0.003 & 0.0004 & 0.004 \\ \text { Others } & & & & & <0.004 \\ & & & & & \text { Sum }=0.160\end{array}$

Table 2. ICP-MS analysis of Be shells produced in B298. The sum is shown both with and without $\mathrm{Cu}$.

\begin{tabular}{cccc} 
Element & $\mathrm{Z}$ & atom\% & $\mathrm{Z} 2 *$ at $\% / 100$ \\
$\mathrm{Cu}$ & 29 & 0.0520 & 0.437 \\
$\mathrm{Fe}$ & 26 & 0.0110 & 0.074 \\
$\mathrm{Ni}$ & 28 & 0.0021 & 0.0165 \\
$\mathrm{Al}$ & 13 & 0.0045 & 0.008 \\
$\mathrm{Mg}$ & 12 & 0.0043 & 0.006 \\
$\mathrm{Ti}$ & 22 & 0.0009 & 0.004 \\
$\mathrm{Cr}$ & 24 & 0.0005 & 0.003 \\
$\mathrm{Mn}$ & 25 & 0.0004 & 0.002 \\
$\mathrm{Mo}, \mathrm{Co}, \mathrm{V}, \mathrm{Zn}, \mathrm{Sc}, \mathrm{Pd}$ & $<0.0001$ & $<0.002$ \\
& & \multicolumn{2}{r}{$\mathrm{Sum}=0.554$} \\
\end{tabular}


The higher level of $\mathrm{Cu}$, at 0.052 atom \% is surprising. Clearly there is residual $\mathrm{Cu}$ in the system that is transferred to the shells even when the $\mathrm{Cu}$ sputter guns are not being used for a given run. What is reassuring with these results is that there are no other surprises, for example an several fold increase in Fe relative to the sputter targets. What is in the targets seems to appear in the shells at about the same concentration.

The elements analyzed and quantified with the ICP-MS technique were specified prior to the experiment so the proper calibration could be performed. However, even if an element isn't specified beforehand, it is still possible to detect it. There was some indication in the ICP-MS results that there might be small amounts of $U$ and $\mathrm{W}$ in the shells, most likely in the $10^{-3}$ atom $\%$ range. If we recalculate the weighted sum of atom fractions using 0.001 atom $\%$ as an estimate for each, then the sum without $\mathrm{Cu}$ is 0.256 . This is slightly higher than the specifications allow. A change to a higher grade of Be (i.e. optical grade) would not necessarily lower the weighted sum of the high- $Z$ impurities. The different categories of Be metal are graded primarily according to their $\mathrm{BeO}$ content. In fact, for the optical grade some of the Brush-Wellman specifications for $\mathrm{Fe}$ and other metallic impurities are actually higher in the optical grade than they are in the "lower" grades such as the S-65 material.

How we deal with these results depends upon how important this level of contamination is. Our guess is that the high $\mathrm{Cu}$ level is due to contamination either from the $\mathrm{Cu}$ gun directly or due to previously sputtered $\mathrm{Cu}$ in the chamber. If the latter it will be a very hard (impossible?) problem to fix. Even without the $\mathrm{Cu}$ problem we are just meeting the specification (to one significant figure). It is unlikely that we can get significantly purer Be targets (but we will inquire). Based on our results we think that the specification needs to be re-evaluated. Can the capsule in the nominally $\mathrm{Cu}$ free regions tolerate a 0.05 atom $\% \mathrm{Cu}$ level? Can the sum of the contributions of other elements (atom fraction $* \mathrm{Z}^{2}$ ) be as much as 0.4 ? Based upon these answers we will determine a path forward. In the mean time we plan to submit a second sample for analysis to include other elements $(\mathrm{U}, \mathrm{W}, \ldots)$ that were seen in this sample but not carefully analyzed for. 


\section{Distribution:}

Craig Alford - alford1@llnl.gov

Jeff Atherton - atherton1@1lnl.gov

Sasa Bajt - bajt@1lnl.gov

Steve Buckley - buckley3@1lnl.gov

Rip Collins - collins7@1lnl.gov

Bob Cook - bobcook@llnl.gov

Gary Deis - deis1@llnl.gov

Tom Dittrich - dittrich1@llnl.gov

John Edwards - edwards39@1lnl.gov

Janelle Gunther - gunther2@1lnl.gov

Steve Haan - haan1@1lnl.gov

Bruce Hammel - hammel1@llnl.gov

Alex Hamza - hamza1@llnl.gov

Mark Herrmann - herrmann3@1lnl.gov

Jeff Klingmann - klingmann1@llnl.gov

Nino Landen - landen1@llnl.gov

Steve Letts - letts1@1lnl.gov

John Lindl - lindl1@llnl.gov

Evan Mapoles - mapoles1@llnl.gov

Marty Marinak - marinak1@llnl.gov

Rand McEachern - mceachern1@llnl.gov

Mike McElfresh - mcelfresh1@llnl.gov

John Moody - moody4@llnl.gov

John Taylor - jstaylor@llnl.gov

Russell Wallace - wallace11@1lnl.gov 
Neil Alexander GA - alexander@fusion.gat.com

Tom Bernat GA - bernat@fusion.gat.com, bernat2@1lnl.gov

Jason Cooley LANL - cooley@lanl.gov

Hiabo Huang GA - huang@fusion.gat.com

Abbas Nikroo GA - nikroo@fusion.gat.com

Art Nobile LANL - anobile@lanl.gov

Richard Stephens GA - stephens@fusion.gat.com

Doug Wilson LANL - dcw@lanl.gov

Hongwei Xu GA - xuh@fusion.gat.com 